Article

\title{
Ecological Interactions between Cork Oak (Quercus suber L.) and Stone Pine (Pinus pinea L.): Results from a Pot Experiment
}

\author{
Alexandra C. Correia *, António Galla, Alexandra Nunes and João S. Pereira \\ Forest Research Centre, School of Agriculture, University of Lisbon, Tapada da Ajuda, 1349-017 Lisbon, Portugal; \\ antonio.guerreiro.galla@gmail.com (A.G.); xanavnunes@isa.ulisboa.pt (A.N.); jspereira@isa.ulisboa.pt (J.S.P.) \\ * Correspondence: alexandrac@isa.ulisboa.pt; Tel.: +351-213-65345
}

Received: 27 July 2018; Accepted: 30 August 2018; Published: 1 September 2018

check for updates

\begin{abstract}
Portuguese cork oak (Quercus suber L.) extended mortality and lack of regeneration have been the drivers of important changes in the traditional cork oak woodlands (savanna-like) montado. The decrease in tree cover fosters the mixture with stone pine (Pinus pinea L.) for pine-nut production providing shelter for oak regeneration. The use of nurse species, namely pines, to help Quercus spp. regeneration is known, but whether cork oak could be favoured by the mixture with stone pine remains a question. A pot experiment with cork oak (Qs) and stone pine (Pp) growing in inter- $(\mathrm{Qs} \times \mathrm{Pp})$ and intraspecific mixtures $(\mathrm{Qs} \times \mathrm{Qs}, \mathrm{Pp} \times \mathrm{Pp})$ combinations and in monocultures, was installed in a greenhouse in Lisbon, Portugal. Morphological measurements of above- and belowground biomass components were carried out in 3 harvesting campaigns at 4, 8 and 11 months. Leaf nitrogen content and mycorrhizal symbiotic formations were quantified. During the seedling stage and under comfort water and nutrient conditions, the root growth and morphology of Qs and Pp showed contrasting patterns, suggesting complementary soil exploitation interactions in interspecific mixtures and potential competition in intraspecific mixtures. The mixture of Qs with Pp seems to be advantageous in the first stages of plant growth as Pp develop abundant mycorrhizae symbiosis formations which elicit mycorrhization of Qs plants coexisting in the same pot. This study suggests that stone pine can potentially help in establishing cork oak as seedlings, possibly facilitating nutrient uptake through mycorrhizae. However, complementary field studies are needed.
\end{abstract}

Keywords: competition; facilitation; complementarity; Mediterranean; mixed forest; greenhouse; mycorrhizae symbiosis

\section{Introduction}

Portugal is responsible for more than half of the world's production of cork. Cork is harvested from adult cork oak (Quercus suber L.) trees in open woodlands (savanna-like) or closed canopy stands. The current state of vulnerability, particularly associated with mortality, dieback and lack of natural regeneration [1], have been driving important changes in cork oak woodlands structures which are now sparser than in the past. This may be explained as the effect of a combination of stresses which include droughts [2] and a higher susceptibility to pests and diseases, namely to the root-rot pathogen Phytophthora cinnamomi [3]. In addition, tilling to avoid shrub encroachment can destroy the root system in the upper soil layers, leading to a greater exposure to water shortage [4]. These are clear disincentives to investment in afforestations which can trigger future cork oak sustainability in its present distribution area.

In parallel, we observe a considerable interest of Portuguese landowners in the densification of cork oak areas with stone pine, especially in the largest and most productive cork oak woodland areas of central and south Portugal affected by cork oak dieback. 
In Portugal the two species share the same ecological areas: the central-southwest regions where milder winter temperatures allow easy settlement and growth. Although both species show a high tolerance to nutrient depleted soils and to low annual precipitation (above $300 \mathrm{~mm}$ ), they are both very sensitive to high hydromorphic soils with low water retention capacity. Leaf area expansion in both species occurs from spring and early summer (May-July) with cones and cork growing concomitantly. Water and nutrient resource needs are highest during this period, suggesting similar environmental resource exploitation strategies. Although much investigation has been dedicated to the ecophysiological functioning of Quercus suber $[5,6]$ stone pine is much less studied.

In Portugal, the combination of cork production, harvested every 9 years, with annual cone production, provides significant revenue to landowners which cannot be neglected in a context where desertification and rural abandonment must be counteracted. According to national reports, stone pine area will likely increase in the future due to its economic interest associated with the high level of ecological plasticity and adaptation capacity to varying edaphoclimatic conditions [7].

Stone pine offers considerable revenue to Mediterranean forest rural communities because pine seeds, produced mostly from naturally regenerated stands, are currently highly prized in international markets [7]. Using the grafting technique, it is possible to anticipate cone production at the age of 5-10 years, providing income sooner than other economically viable Mediterranean woody species [8].

Oak-pine forest mixtures are often considered as transient stages in ecological succession, assuming that pines may facilitate the establishment of late-successional species like oaks $[9,10]$. It is likely that complementary interactions may predominate between pines and oaks as Mediterranean pines are considered drought-avoiding species, sharing space and resources with drought-tolerant evergreen oaks. In limited environmental conditions, and especially in the Mediterranean region where soil nutrients and water is scarce, it is not consensual whether competition [11] or facilitation [12] dominate.

Facilitation processes seem to be species and locale specific. A study conducted by Fruleux et al. [13] combining Fagus sylvatica L. and Quercus petraea (Matt) Liebl. showed that under dry conditions, facilitation processes of Quercus prevailed over Fagus, while under well irrigated conditions the opposite was observed. Similar results were obtained by [14] studying mature stands of beech and Quercus sp. in Europe. Other authors found exactly the opposite. Jucker et al. [15] for example, observed a 48\% increase in above-ground woody biomass in mixture of Iberian oaks and pines species, but under drought stress years, competition prevailed. The reason given is related with the ability to exploit soil water and nutrients by the differentiated species' root systems.

In fact, root attributes relating function, morphology and distribution, seem to provide more consistent responses to species interactions than the aboveground component [16-21]. A study conducted by del Castillo and co-authors [22] was able to trace the dynamics of water use in a mixed oak-pine (Pinus halepensis Miller and Quercus ilex L.) Mediterranean field experiment during summer using the stable isotope composition method. They found a shift of oak roots to deep-soil forced by the presence of pines in the shallowed soil layers. A similar result was obtained [17] in a field experiment mixture of beech and spruce, where a downwards shift in beech fine roots was observed to deeper soil layers due to interspecific competition. In conclusion, trees respond to the presence of others throughout root morphological adaptations, stratifying over the soil profile similarly to what leaves do in the search for light.

In addition, it is also important to refer to the role of mycorrhizal fungi and bacterial associations especially for a successful establishment of tree seedlings. Both pine and oak form ectomycorrhizal symbioses that cover their roots and extend into the soil, facilitating tree water and nutrient uptake in exchange for photosynthetic carbon $[23,24]$. These associations also increase plant tolerance to different environmental stresses, either biotic or abiotic. It is possible that these root-soil attributes drive the response of species mixture interactions but these are extremely difficult to measure and quantify in woody species under field conditions. These studies are scarce but needed. 
In Mediterranean climates, reduced annual precipitation amounts lead to long periods of soil water shortage which, associated with nutrient depleted soils, are serious threats to cork oak establishment and survival. In cork oak woodlands tree density is naturally low, which reflects the ecological system's capacity to support only a small fraction of leaf area. In such conditions, competition among coexistent plant communities seems to dominate either between trees [22] with trees, herbaceous vegetation [25] or shrubs [26]. Increasing the number of individuals per unit area or mixing cork oak with highly competitive species may threaten tree growth and vitality and exacerbate mortality.

There are no studies addressing specific interactions between Quercus suber and Pinus pinea L. Although the mixture of stone pine and cork oak have always occurred in the past as a result of natural regeneration, the consequences of such widespread growth in the present and, most likely in the future, remains unclear in a future global economic and climate change context.

Understanding plant ecological interactions in a mixed species context is challenging due to the lack of effective approaches for access and monitoring. The difficulty increases when dealing with slow growing species such as cork oak. Pot experiments are therefore an alternative. Due to the controlled environmental conditions, the results are faster to obtain and easier to interpret, and they can be repeated as often as required without the influence of natural environmental variability which occurs naturally under field conditions which are also difficult to control and monitor [27]. Clear disadvantages are related with woody species dimensions and longevity which are limited by pot size and therefore usually restricted to the early stages of seedling and sapling growth. Although pot experiment results can hardly be translated to field conditions, they allow hypotheses to be drawn for testing under field conditions.

In this work we tested the following hypotheses: (i) complementarity interactions should predominate between stone pine and cork oak because, although they share the same ecological areas, they differ in the use of environmental resources and therefore complement each other functionally; (ii) inter- or intra-specific mixtures differences, if any, would be noticeable in root traits because in Mediterranean species life-forms, the development of the root systems is essential to ensure seedling establishment; and (iii) there are empirical evidences that Quercus suber regenerate better under pine canopy layers, so soil-related processes may help to explain species interactions.

The main aim of this study is to investigate whether spatial segregation exists between stone pine and cork oaks and which ecological interaction (competition, facilitation or complementary) predominates. For this purpose, we ran a pot experiment where intra- and interspecific mixtures of stone pine and cork oak seedlings were combined in well-watered and ample fertility conditions, evaluating morphological attributes in aboveground and belowground components over time. We intend to provide knowledge to support forest management recommendations for mixed Quercus suber and Pinus pinea species afforestation planning.

\section{Materials and Methods}

\subsection{Plant Material}

The acorns and pine seeds were collected in winter 2016 in a mixed natural stand of Quercus suber $\mathrm{L}$. and Pinus pinea L. located in Vendas Novas (Lat, Long: $38.751619^{\circ} \mathrm{N},-8.538451^{\circ} \mathrm{W}$ ) and representative of the distribution area of the mix of both species in Portugal. The acorns were harvested from a tree in November 2016 while the pine seeds were selected from a cone, harvested in January 2016. The objective of using half-sibs was to reduce growth responses due to genetic variability among plants. The seeds were collected from healthy trees with no visible symptoms of diseases. Acorns were picked directly from the tree and immersed in water for $48 \mathrm{~h}$ in order to discard the damaged floating ones. The cone was placed in an oven during one week at $55^{\circ} \mathrm{C}$ in order to allow the scales to open and the removal of the pine seeds. The acorns and pine seeds were stored in a conventional refrigerator at $4{ }^{\circ} \mathrm{C}$ until the start of the experiment. 
Both pine nuts and acorns were germinated on a moistened compost seed-bed at $25^{\circ} \mathrm{C}$ and were both ready for transplantation after 15 days, when a radicle of approximately $1-3 \mathrm{~cm}$ was visible. The seeds were then transplanted to $7.5 \mathrm{dm}^{3}$ pots (height of $32 \mathrm{~cm}$ and diameter of $18.5 \mathrm{~cm}$ ) filled with a peat and sand mixture $(4: 1, v / v)$.

\subsection{Greenhouse Conditions}

The experiment was carried out from 30 March 2017 until 28 February 2018 in an open greenhouse located in the Institute Superior of Agronomy, Lisbon. Natural precipitation was excluded by a glass ceiling which intercepted $30 \%$ of incoming radiation while air temperature and humidity were similar to outside conditions. A dripping irrigation system was installed in order to control the amount of water added to each pot. Soil field capacity (approximately 18\% for the substrate mixture used in this experiment) was calculated in the beginning of the experiment by soaking one pot filled with the soil mixture with a fixed amount of water and letting it set for 1 day. The difference between the amount of water initially added and the water drained by gravity action corresponds to the water contained in the soil macropores and therefore available for the plants. This amount of water was maintained constant over the experiment by controlling the dripping irrigation debit. We additionally measured soil water content continuously at depths of 5 and $20 \mathrm{~cm}$, with soil sensors (ECH2O EC-5, METER Group, Inc., Pullman, WA, USA). In each harvesting campaign, soil water content was measured gravimetrically in 4 pots, confirming the watering at sufficiency. Fertigation occurred in the middle of the experiment (30 September 2017) using an NPK equilibrated mixture of $14+7+14$. The watering regime was slightly adjusted after each harvesting campaign and according to the weather conditions, in particular with air temperature and relative humidity during summer which decreased the amount of superficial available water.

\subsection{Experimental Design}

The experiment was carried out in a split-plot design with 5 species combinations of Pinus pinea (Pp) and Quercus suber (Qs): one plant per pot (Qs or Pp), two plants of the same species per pot (the intraspecific combinations $\mathrm{Q} s \times \mathrm{Qs}$ and $\mathrm{Pp} \times \mathrm{Pp}$ ) and two plants of different species per pot (interspecific combinations $\mathrm{Qs} \times \mathrm{Pp}$ ), with a total of 18 replicates per combination totalling 90 pots. The designation Qs $\times \mathrm{Pp}$ and $\mathrm{Pp} \times \mathrm{Qs}$ corresponds to same interspecific mixture in the same pot, but with the first two letters referring to the species under evaluation. In the intraspecific mixtures, $\mathrm{D}$ and $\mathrm{X}$ corresponds to the relative position of the plant in the mixture, with D standing for dominant and $X$ for the supressed plant (classification based on total plant biomass at each harvesting campaign).

\subsection{Plant Measurements}

\subsubsection{Monthly Measurements}

Twenty days after epicotyls emerged, monthly aboveground measurements started for the following variables: (1) plant total height in all plants, (2) total number of leaves in cork oaks and (3) number of twigs in cork oaks and stone pine. Height growth rate $\left(\mathrm{GR}_{\text {height }}\right)$ was calculated as the difference between heights measured between consecutive measurement dates.

\subsubsection{Destructive Sampling}

Three destructive samplings were carried out at age 4, 8 and 11 months with an equal number of pots harvested at each time (that is, 30 pots in each harvesting campaign with 6 replicates per treatment). The following variables were evaluated for each plant: (1) number, one side total leaf area and dry weight of leaves, (2) stem base diameter, length and stem dry weight, (3) number of twigs and length, (4) total root length, surface area and roots dry weight for roots with diameter higher than $2 \mathrm{~mm}$ (coarse roots) and lower than $2 \mathrm{~mm}$ (fine roots), and (5) nitrogen content in leaves at 11 months (total nitrogen content by combustion using the Dumas method). The presence/absence of mycorrhizae associations was also recorded in each plant root. 
The dry weight was calculated by placing each biomass component in oven for 2 days at $65^{\circ} \mathrm{C}$. The Winseedle Software (Regent Instruments Inc., Quebec, QC, Canada) was used to calculate one side projected leaf area for cork oak and stone pine, root length and total surface area.

\subsection{Statistical Analysis}

To examine the differences between treatments, we used One Way Repeated Measures Analysis of Variance (ANOVA). When statistically significant differences were found, differences between group means were identified by post hoc Tukey HSD (honestly significant difference) tests with a significance value for multiple comparisons of 0.05 . When ANOVA assumptions were not fulfilled, i.e., no normal distribution of the data and/or homogeneity of variances, non-parametric tests were carried out performing a comparison on ranks, with Dunn's test being used for post hoc pairwise comparisons. The Pearson Product Moment Correlation coefficient was used to display the strength of the association between pairs of variables. All statistical relationships were considered significant at $p<0.05$. Statistical analyses were carried out using SigmaPlot V13.0 (SigmaStat for windows, Dundas Software, Erkrath, Germany).

\section{Results}

\subsection{Height Growth Rate}

During the first 2 months of the experiment, Qs presented a steep height growth increment, almost 4 times higher than Pp (Figure 1). From August onwards, this decreased sharply to values close to Pp. On average, daily Qs growth was slightly higher $\left(0.068 \pm 0.009 \mathrm{~cm} \mathrm{day}^{-1}\right)$ than Pp with $0.043 \pm 0.004 \mathrm{~cm}$ day $^{-1}$. Except in the first 2 month of plant development, no significant differences were observed between species or between the treatments regarding $G_{\text {height }}$. The intermediate fertigation in September stimulated height growth in both species, branching and the formation of new leaves. The total number of new leaves increased $48 \%$ in Qs and branching in Pp (22\%) and in Qs $(57 \%)$, irrespective of the treatment.

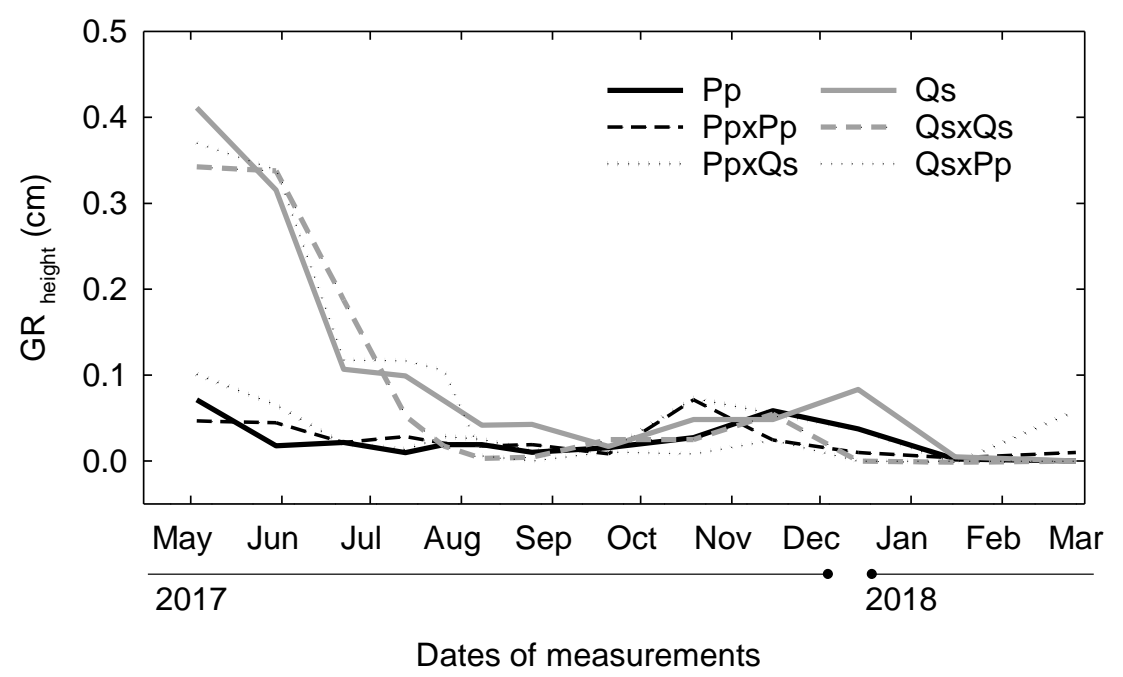

Figure 1. Height growth rate $\left(\mathrm{GR}_{\text {height }}\right)$ for each species and species combination during the experiment.

\subsection{Biomass Partitioning}

\subsubsection{Quercus suber (Qs) vs. Pinus pinea (Pp)}

Substantial morphological differences were observed between Qs and Pp regarding the root system (Figures 2 and 3). One of the most noticeable features of Qs was the development of a thick and deep lignified taproot which rapidly reached the base of the pot. Fine roots in Qs with less than 
$2 \mathrm{~mm}$ were only $10 \%$ of the total root biomass irrespective of the harvesting campaign, and branching preferably in the deeper soil pot layer. A fibrous root system characterized Pp, consisting of a complex of dense and slender, adventitious roots. Pp had approximately $35 \%$ more fine root biomass than Qs, on average, for all the 3 harvesting campaigns. Conversely, total aboveground biomass was $30 \%$ higher in Qs, on average, for the 3 harvesting campaigns with leaves biomass representing $67 \%$ and stems $33 \%$. For Pp, leaves represented $81 \%$ and stem $19 \%$ of the aboveground biomass. The fraction of root to aboveground biomass (Root/Shoot) (Figure 3 and Table 1) was, on average, 4 times higher in Qs irrespective of the species combination and harvesting campaign. The woody taproot weight was responsible for this significant root/shoot difference between the two species.

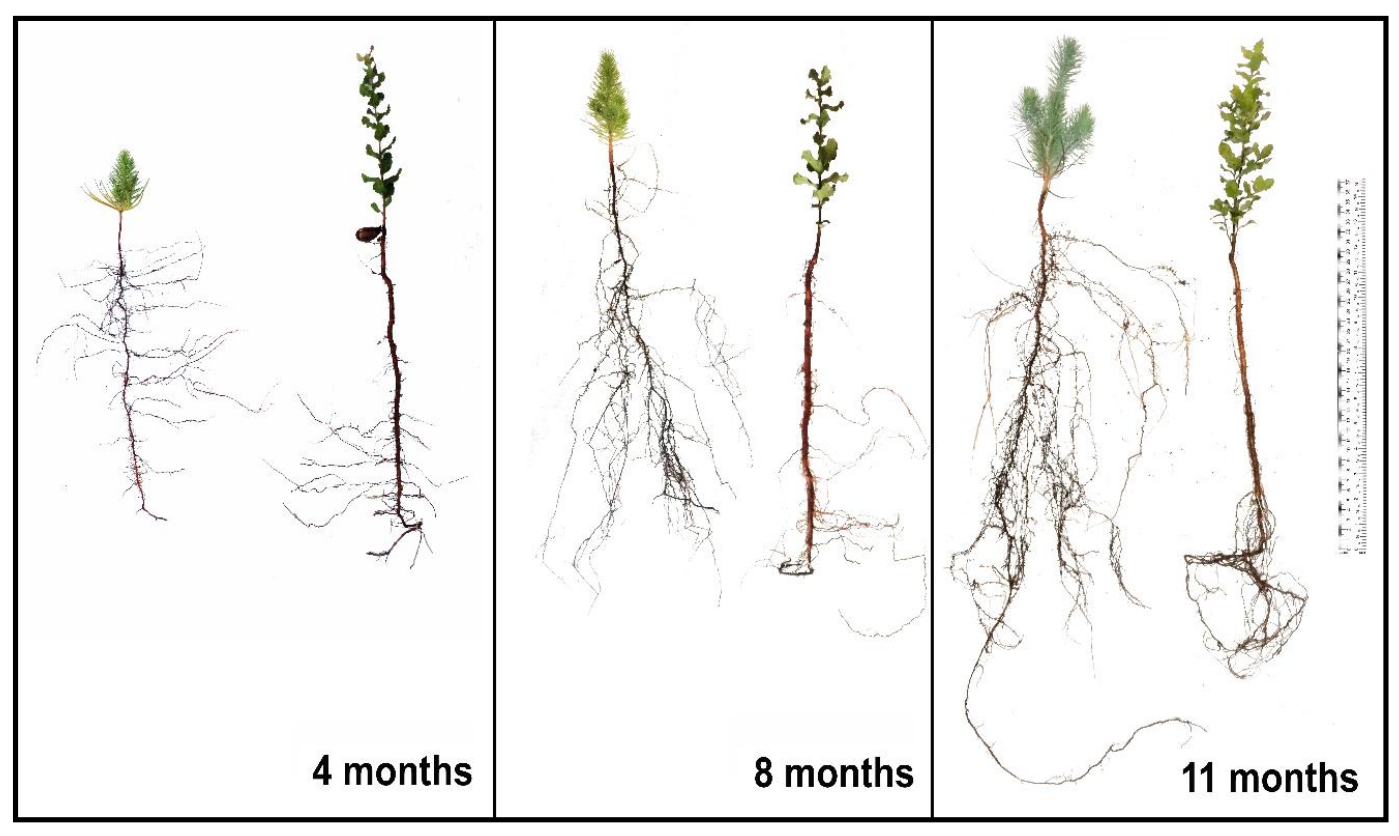

Figure 2. Pictures of Qs and $\mathrm{Pp}$ in the interspecific mixtures at 4, 8 and 11 months growing in the same pot.

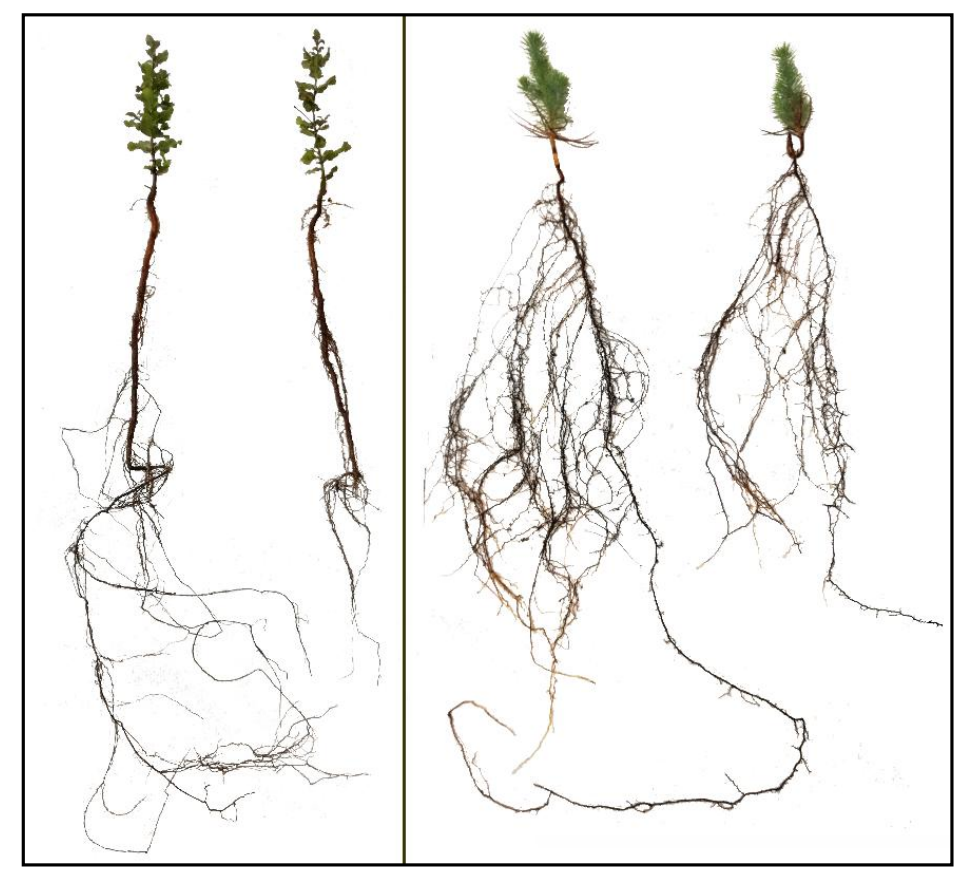

Figure 3. Pictures of Qs and Pp growing in the same pot, that is, in the intraspecific mixture at 11 months. 
Table 1. Morphological measurements in each harvesting campaign for Quercus suber (Qs) and Pinus pinea (Pp) for the following variables: Specific leaf area, $\left(\mathrm{cm}^{2} \mathrm{~g}^{-1}\right)$, Leaf area (total one-side) $\left(\mathrm{cm}^{2}\right)$, Leaf biomass (g), Fine root biomass (g), Root Length $(\mathrm{cm})$, Root/Shoot, Fine Root/Shoot and Total biomass (g). D and X stand for the relative positions of the plant in the mixture: $\mathrm{D}$ for the dominant and $\mathrm{X}$ for the supressed plant. Different letters $(\mathrm{a}$ and $\mathrm{b})$ stands for significand differences between the average values within each variable and species combination.

\begin{tabular}{|c|c|c|c|c|c|c|c|c|c|c|c|}
\hline & & $\begin{array}{l}\text { Specific Leaf } \\
\text { Area }\left(\mathrm{cm}^{2} / \mathrm{g}\right)\end{array}$ & $\begin{array}{l}\text { Leaf Area } \\
\left(\mathrm{cm}^{2}\right)\end{array}$ & $\begin{array}{c}\text { Leaf } \\
\text { Biomass (g) }\end{array}$ & $\begin{array}{c}\text { Fine Root } \\
\text { Biomass (g) }\end{array}$ & $\begin{array}{l}\text { Root Length } \\
\text { (cm) }\end{array}$ & Root/Shoot & $\begin{array}{c}\begin{array}{c}\text { Fine } \\
\text { Root/Shoot }\end{array} \\
\end{array}$ & $\begin{array}{l}\text { N Content } \\
\mathrm{g} \mathrm{kg}^{-1}\end{array}$ & $\begin{array}{l}\text { Total Biomass } \\
(\mathrm{g})\end{array}$ & $\begin{array}{c}\text { Mycorryzae } \\
(\%)\end{array}$ \\
\hline \multirow{8}{*}{$\begin{array}{l}\text { 1st harvest } \\
\text { (4 months) }\end{array}$} & $\mathrm{Pp}$ & $50 \pm 0.50$ & $45.3 \pm 3.21 \mathrm{a}, \mathrm{b}$ & $0.9 \pm 0.07$ & $0.7 \pm 0.05$ & $930 \pm 102$ & $0.7 \pm 0.02$ & $0.68 \pm 0.02$ & - & $1.7 \pm 0.13 \mathrm{a}, \mathrm{b}$ & 0 \\
\hline & $\operatorname{PpxPp}(D)$ & $50 \pm 1.3$ & $47.7 \pm 1.52 \mathrm{a}, \mathrm{b}$ & $1 \pm 0.04$ & $0.7 \pm 0.04$ & $1004 \pm 99$ & $0.6 \pm 0.02$ & $0.63 \pm 0.02$ & - & $1.8 \pm 0.08 \mathrm{a}, \mathrm{b}$ & 0 \\
\hline & $\operatorname{PpxPp}(X)$ & $52 \pm 1.5$ & $36.3 \pm 4.88^{\mathrm{a}}$ & $0.7 \pm 0.09$ & $0.5 \pm 0.06$ & $760 \pm 126$ & $0.7 \pm 0.02$ & $0.65 \pm 0.02$ & - & $1.3 \pm 0.17^{\mathrm{a}}$ & 0 \\
\hline & PpxQs & $50 \pm 0.7$ & $49 \pm 2.62^{b}$ & $1 \pm 0.05$ & $0.7 \pm 0.04$ & $991 \pm 66$ & $0.6 \pm 0.04$ & $0.64 \pm 0.04$ & - & $1.8 \pm 0.08^{a, b}$ & 0 \\
\hline & Qs & $76 \pm 2.9$ & $76.2 \pm 11.78$ & $1 \pm 0.19$ & $0.4 \pm 0.04$ & $1520 \pm 199$ & $3.4 \pm 0.35$ & $0.32 \pm 0.03$ & - & $6 \pm 0.61 \mathrm{a}, \mathrm{b}$ & 0 \\
\hline & QsxQs(D) & $78 \pm 3.0$ & $83.8 \pm 9.05$ & $1.1 \pm 0.13$ & $0.6 \pm 0.2$ & $1376 \pm 183$ & $3.4 \pm 0.29$ & $0.4 \pm 0.17$ & - & $6.7 \pm 0.5^{a}$ & 0 \\
\hline & QsxQs $(X)$ & $78 \pm 3.1$ & $66.2 \pm 10.17$ & $0.9 \pm 0.14$ & $0.6 \pm 0.16$ & $1405 \pm 305$ & $2.9 \pm 0.43$ & $0.62 \pm 0.25$ & - & $4.5 \pm 0.7^{b}$ & 0 \\
\hline & QsxPp & $80 \pm 1.5$ & $58.9 \pm 3.74$ & $0.7 \pm 0.06$ & $0.3 \pm 0.06$ & $1009 \pm 116$ & $3.9 \pm 0.17$ & $0.3 \pm 0.05$ & - & $4.9 \pm 0.16^{\mathrm{a}, \mathrm{b}}$ & 0 \\
\hline \multirow{8}{*}{$\begin{array}{c}\text { 2nd } \\
\text { harvest } \\
\text { (8 months) }\end{array}$} & $\mathrm{Pp}$ & $50 \pm 2.3$ & $51.4 \pm 8.19^{a}$ & $1 \pm 0.13$ & $1.1 \pm 0.05$ & $1702 \pm 194$ & $0.9 \pm 0.08$ & $0.89 \pm 0.08$ & - & $2.4 \pm 0.18^{a}$ & $50 \%$ \\
\hline & $\operatorname{PpxPp}(D)$ & $57 \pm 3.0$ & $88.9 \pm 8.37^{b}$ & $1.5 \pm 0.09$ & $1.5 \pm 0.07$ & $1994 \pm 104$ & $0.8 \pm 0.04$ & $0.77 \pm 0.04$ & - & $3.5 \pm 0.15^{b}$ & $67 \%$ \\
\hline & $\operatorname{PpxPp}(X)$ & $66 \pm 9.6$ & $79.5 \pm 7.29 \mathrm{a}, \mathrm{b}$ & $1.3 \pm 0.11$ & $1.2 \pm 0.1$ & $1752 \pm 139$ & $0.7 \pm 0.04$ & $0.75 \pm 0.04$ & - & $2.8 \pm 0.22^{a b}$ & $67 \%$ \\
\hline & PpxQs & $56 \pm 3.2$ & $84.6 \pm 11.8^{a, b}$ & $1.5 \pm 0.17$ & $1.3 \pm 0.12$ & $1642 \pm 100$ & $0.7 \pm 0.06$ & $0.72 \pm 0.06$ & - & $3.3 \pm 0.29^{\mathrm{a}, \mathrm{b}}$ & $67 \%$ \\
\hline & Qs & $74 \pm 2.4$ & $121.1 \pm 9.73$ & $1.6 \pm 0.11$ & $0.6 \pm 0.05$ & $2045 \pm 235$ & $3.4 \pm 0.47$ & $0.24 \pm 0.03$ & - & $10.6 \pm 0.92 \mathrm{a}, \mathrm{b}$ & $17 \%$ \\
\hline & QsxQs(D) & $74 \pm 3.9$ & $167.4 \pm 37.53$ & $2.2 \pm 0.37$ & $1.1 \pm 0.24$ & $3054 \pm 622$ & $3 \pm 0.6$ & $0.33 \pm 0.07$ & - & $12.3 \pm 0.75^{\mathrm{a}, \mathrm{b}}$ & $0 \%$ \\
\hline & QsxQs $(X)$ & $72 \pm 4.1$ & $140.3 \pm 37.95$ & $1.9 \pm 0.4$ & $1.1 \pm 0.33$ & $2584 \pm 750$ & $2.7 \pm 0.46$ & $0.4 \pm 0.11$ & - & $9.1 \pm 1.03^{a}$ & $0 \%$ \\
\hline & QsxPp & $70 \pm 3.7$ & $156.3 \pm 25.2$ & $2.2 \pm 0.29$ & $0.9 \pm 0.29$ & $1929 \pm 397$ & $3 \pm 0.39$ & $0.27 \pm 0.07$ & - & $12.7 \pm 0.82^{b}$ & $50 \%$ \\
\hline \multirow{8}{*}{$\begin{array}{l}\text { 3rd harvest } \\
\text { (11 months) }\end{array}$} & $\mathrm{Pp}$ & $59 \pm 3.7$ & $99.5 \pm 14.27$ & $1.7 \pm 0.17$ & $2.2 \pm 0.2$ & $3040 \pm 379^{a}$ & $1 \pm 0.07$ & $1.01 \pm 0.07$ & $11 \pm 1.8$ & $4.3 \pm 0.35$ & $100 \%$ \\
\hline & $\operatorname{PpxPp}(D)$ & $72 \pm 10.8$ & $130.3 \pm 15.42$ & $1.9 \pm 0.16$ & $2.2 \pm 0.11$ & $2764 \pm 116^{a, b}$ & $0.9 \pm 0.06$ & $0.92 \pm 0.06$ & $13.1 \pm 2.7$ & $4.6 \pm 0.25$ & $50 \%$ \\
\hline & $\operatorname{PpxPp}(X)$ & $78 \pm 14.9$ & $120.3 \pm 25.83$ & $1.5 \pm 0.17$ & $1.6 \pm 0.11$ & $1950 \pm 169^{b}$ & $0.8 \pm 0.07$ & $0.83 \pm 0.07$ & $12.4 \pm 2.7$ & $3.5 \pm 0.32$ & $83 \%$ \\
\hline & PpxQs & $64 \pm 4.4$ & $126.6 \pm 22.88$ & $1.7 \pm 0.28$ & $1.8 \pm 0.19$ & $1983 \pm 185^{a, b}$ & $0.8 \pm 0.07$ & $0.84 \pm 0.07$ & $12.8 \pm 2.4$ & $4 \pm 0.55$ & $67 \%$ \\
\hline & Qs & $70 \pm 2.2$ & $140.8 \pm 20.74$ & $2 \pm 0.31$ & $1.1 \pm 0.29$ & $2204 \pm 255$ & $4.3 \pm 0.66$ & $0.38 \pm 0.07$ & $15.3 \pm 0.8$ & $14.9 \pm 1.51^{\mathrm{a}}$ & $17 \%$ \\
\hline & QsxQs(D) & $70 \pm 2.2$ & $100.4 \pm 17.29$ & $1.4 \pm 0.23$ & $0.7 \pm 0.07$ & $1470 \pm 168$ & $4.8 \pm 0.54$ & $0.4 \pm 0.06$ & $14.2 \pm 0.9$ & $11.3 \pm 0.87^{a, b}$ & $0 \%$ \\
\hline & QsxQs $(X)$ & $73 \pm 1.8$ & $125.8 \pm 17.2$ & $1.7 \pm 0.2$ & $0.9 \pm 0.16$ & $2228 \pm 591$ & $3 \pm 0.12$ & $0.34 \pm 0.05$ & $14.3 \pm 0.6$ & $10.4 \pm 1.02^{b}$ & $33 \%$ \\
\hline & QsxPp & $79 \pm 3.6$ & $151.9 \pm 19.38$ & $1.9 \pm 0.23$ & $1.1 \pm 0.22$ & $1570 \pm 157$ & $3.6 \pm 0.32$ & $0.4 \pm 0.08$ & $14.9 \pm 0.7$ & $12.6 \pm 0.84^{\mathrm{a}, \mathrm{b}}$ & $67 \%$ \\
\hline
\end{tabular}




\subsubsection{Species Combinations}

Quercus suber (Qs)

The most important differences between Qs plant combinations were related with the root system (Table 1, Figure 4) and were uncoupled with the aboveground biomass. The most productive Qs plants at the end of the experiment at 11 months were the ones growing alone (Table 1). This pattern was not observed in the previous harvesting campaigns at 4 and 8 months old (Figure 4, Table 1) where the dominant plants of the intraspecific mixtures were the most productive, that is Qs $\times$ Qs $(D)$, or in combination with $\mathrm{Pp}(\mathrm{Qs} \times \mathrm{Pp})$. Conversely, the supressed Qs in the intraspecific mixture, $\mathrm{Qs} \times \mathrm{Qs}(\mathrm{X})$, showed systematically lower root and total plant biomass in the three harvesting campaigns. This trend was accompanied by a reduction in the Root/Shoot ratio but the total fine root production and root length were not affected, and in fact were higher than the dominant neighbour plant of the pot. The supressed plants invested much more in the fine root system leading also to a higher leaf area.
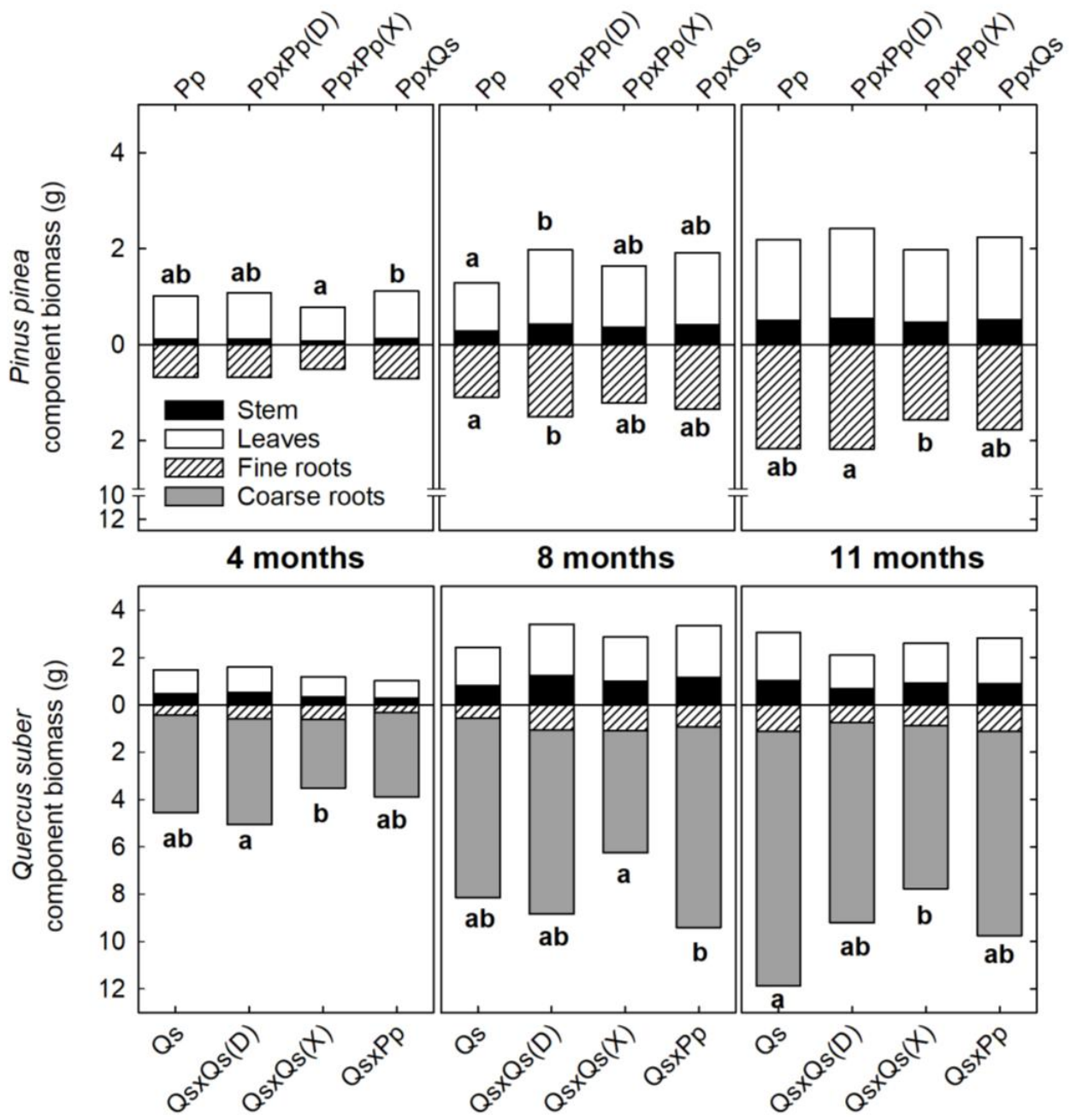

Figure 4. Biomass partition in Quercus suber (Qs) and Pinus pinea (Pp) for the three harvesting campaigns at 4, 8 and 11 months old and for the different species mixtures. One plant per pot (Qs or Pp), two plants of the same species per pot (the intraspecific combinations $\mathrm{Qs} \times \mathrm{Qs}$ and $\mathrm{Pp} \times \mathrm{Pp}$ ) and two plants of different species per pot (interspecific combinations $\mathrm{Q} s \times \mathrm{Pp}$ or $\mathrm{Pp} \times \mathrm{Qs}$, the first two letters varying according to the species under evaluation). D stands for the dominant and $\mathrm{X}$ for the supressed plant in the mixture. Significant differences $(p<0.05)$ between Qs and Pp combinations for each harvesting campaign represented by different letters ( $\mathrm{a}$ and $\mathrm{b}$ ). Bars above 0 for aboveground biomass and under 0 for the root biomass). 
Total one side-leaf area and leaf biomass did not show statistical differences for Qs but did for Pp at 4 and 8 months. Pp mixed with Qs were among the Pp plants with the highest biomass recorded. The SLA did not changed significantly between plant combinations although a decreasing trend was observed in Qs in each of the successive campaigns. Leaves increased in weight more than area and became more sclerified.

Pinus pinea $(\mathrm{Pp})$

Both above- and belowground biomass differed significantly between Pp combinations along the three harvesting campaigns (Figure 4). At the end of the experiment (11 months), the Pp growing in intraspecific combination was more productive (aboveground and roots), had higher leaf biomass and area, while the supressed Pp the lowest (Table 1). No significant differences were observed between plant combinations for total biomass. The Pp growing in isolation showed a significantly higher root length and root/shoot. All the isolated Pp plants presented mycorrhizae symbiosis at 11 months.

The root/shoot was comparable between the Pp plant combinations varying between 0.8 and 1 , and four time lower than in Qs (Table 1). Contrary to what was observed for Qs, the SLA increased with the successive campaigns and the lowest values were found in isolated Pp plants at the final harvest at 11 months, although not statistically significant from the other plant combinations.

\subsection{Leaf Nitrogen (N) Content}

The average $\mathrm{N}$ content in the leaves at 11 months was $14.7 \pm 1.1 \mathrm{~g} \mathrm{~kg}^{-1}$ for cork oak and $12.4 \pm 0.4 \mathrm{~g} \mathrm{~kg}^{-1}$ for stone pine (Table 1). No differences were observed for $\mathrm{N}$ content between plant combinations, neither for $\operatorname{Pp}(p=0.907)$ or for $\mathrm{Qs}(p=0.428)$. However, significant differences were observed between plants with microbial symbiotic associations and without them. For Pp, the N content in infected plants doubled when compared with non-infected plants $(14.2 \pm 0.5$ and $6.8 \pm 2.1$, respectively) (Figure 5).
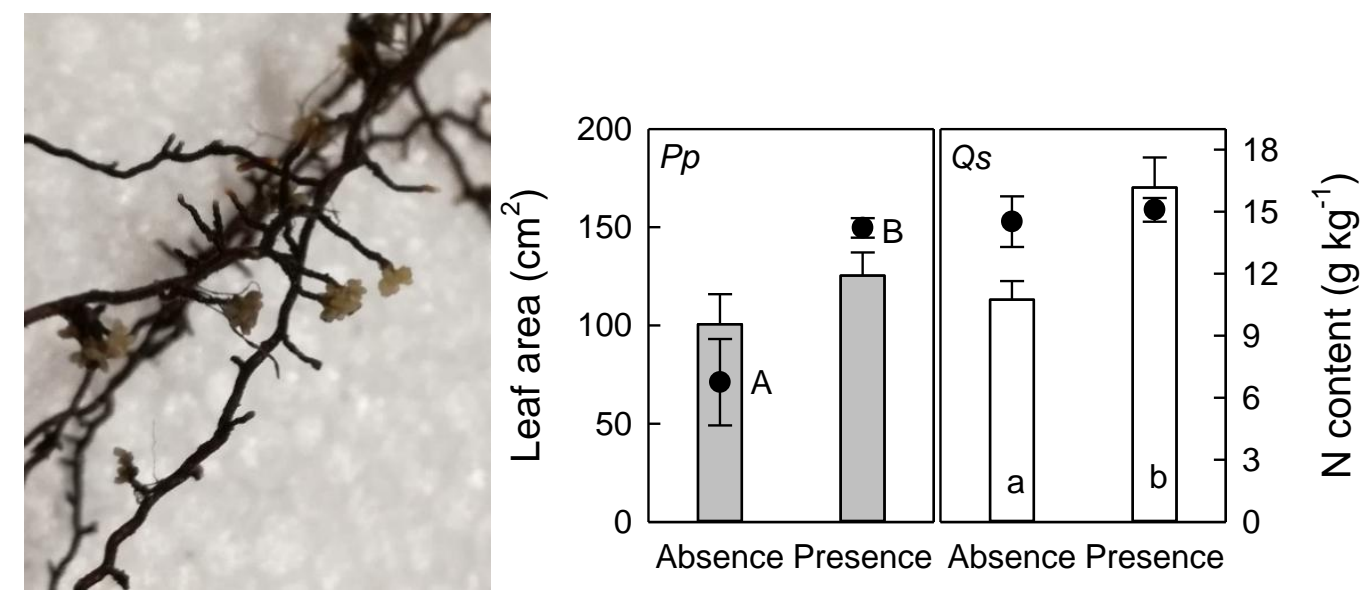

Figure 5. Plant one-side leaf area (bars) in the 3rd harvesting campaign (11 months) in plants with microbial infections (Presence) and without them (Absence) for each species (Pp in grey bars, Qs in white bars). Dots represent average values for $\mathrm{N}$ content in leaves with the corresponding standard error. Letters in small caps ( $a$ and b) show statistical differences for leaf area and all caps (A and B) for the differences for $\mathrm{N}$ content in the leaves. In the left a picture of the mycorrhiza symbiosis found in Pp.

\subsection{Microbial Symbiotic Associations}

Pinus pinea developed a higher number of microbial symbiotic associations (arbuscular ectomycorrhizal fungi in Figure 5) and much sooner than Qs. At 8 months old, 53\% of the 24 Pp plants harvested showed microbial symbiotic associations and at 11 months the ratio increased to $75 \%$ (more 
details for species combination in Table 1). In Qs, the rates were much lower, with $17 \%$ and $29 \%$ at 8 and 11 months, respectively for the 24 plants harvested. The presence of microbial associations was considerably higher in Qs growing in pots together with Pp compared with the isolated plants or in the sibling mixtures (Table 1). However, due to the unbalanced number of plants infected per plant combinations, we were unable to test differences between them. At 11 months, the Qs and Pp plants which developed mycorrhizae associations presented higher aboveground leaf biomass and area but a maintenance or slight decrease in fine root biomass (Table 1). Mycorrhizae symbiosis also lead to a significant higher leaf area at 8 months for Pp (not shown) and at 11 months for Qs.

\section{Discussion}

Mediterranean forests are recognized for the extraordinary variety of non-wood forest products offered, with cork and pine among the most interesting. Climate change, a long history of inadequate management practices, the introduction and spread of pest and diseases are weakening cork oak woodlands resilience, jeopardizing the sustainability of cork production and quality. Despite the afforestation efforts conducted in the last 30 years in Portugal to increase cork oak area, the rate of established plants may not be enough to compensate the mortality recorded systematically every year, exacerbated by unpredictable and large-scale mortality events in extreme dry years (with 2005 and 2017 as examples). To date, there is no knowledge on how to counteract this trend. Can stone pine facilitate the establishment success of cork oak? Do these species complement each other for resource environmental exploitation? How can this study help to answer these questions?

\subsection{Pinus Pinea and Quercus Suber: Different Root Strategies of Soil Exploitation}

Root morphology, growth and architecture of Qs and Pp were remarkably different in the seedling stage, with Qs investing in a woody taproot able to penetrate the deep soil layers very fast and earlier than Pp. While Pp showed a dense lateral fine root development occupying all the pot profile, Qs' fine roots were mostly concentrated in the base of the pot with only a few lateral roots branching from the taproot. This growth pattern was observed in other cork oak greenhouse studies [28]) and also in young and mature trees in natural conditions [5]. As a drought-avoiding species, adult Qs develop a network of sinker roots able to efficiently exploit groundwater during the summer and hydraulically redistribute it to superficial roots, allowing the maintenance of transpiration rates during this critical season. This is an important plant survival strategy in arid and semi-arid regions. However, it is unlikely that such a complex hydraulic system is already efficiently established in early stages of the plant development and able to overcome the Mediterranean summer when the water table drops dozens of meters. Watering during summer in order to avoid premature death may be a solution, but only in particular cases as it is technically and economically impractical for most forest owners. The use of nurse species for this purpose, like stone pine, seems to be viable according to the results of this study, although much more investigation is clearly needed.

In Portugal, young plants need to overcome several other constraints related with nutrient depleted soil with reduced thickness and low water holding capacity [6]. In the initial seedling stage, the construction of woody sinker roots in Qs is made at the expense of less fine root production. The presence of highly compacted subsurface soil horizons is a serious constraint on Qs taproot development leading to root malformations which can lead to root rot infection and jeopardize tree establishment and survival. In already infected soils there is a high change of establishment failure. Fine roots are functionally more efficient in exploiting topsoil volume water and nutrients. Contrary to coarse roots, they quickly regenerate after stress and have a higher predisposition to the formation of microbial symbiotic associations [23]. Comparing the root development of the two species, Pp seems to be in advantage during the seedling stage, showing 4 times more fine root biomass and mycorrhizing much more easily than Qs. This may explain the higher establishment success rates of Pp compared with Qs in adequate ecological regions in Portugal. However, this is unlikely to occur in highly hydromorphic soils which may constrain fine root proliferation. In these types of soil, the root 
capacity of Qs to exploit deep soil layers could be advantageous, but only if the young tap-roots are able to rapidly reach water tables.

\subsection{Positive Interactions of Pp over Qs Linked with Microbial Symbiotic Associations}

The results suggest a better performance of $\mathrm{Pp}$ and Qs in interspecific than in intraspecific mixtures because there is one conspecific that is always dominated by the other. Overall the supressed plant growing with siblings showed lower total biomass than the plants growing isolated or in interspecific mixtures suggesting a predominance of competition interactions. The rooting zone in intraspecific mixtures (that is $\mathrm{Pp} \times \mathrm{Pp}$ or $\mathrm{Qs} \times \mathrm{Qs}$ ) clearly shows an overlap of individuals. As nutrients and water were not limiting, root volume space dominance of one plant over the other may be an explanation for such intraspecific competition behaviour. Some authors [29-31] also refer to the effect of allelopathic interactions resulting from the release of secondary metabolites with inhibitory effects over growth in individuals of the same species, the autotoxicity concept following Mazzoleni et al. [32]. This topic was not studied here but should be addressed in future studies.

The rooting profile of Qs and Pp shows distinct soil depths, with Qs fine roots concentrated in the base and Pp in the middle-top of the pot. Soil niches spaces are therefore clearly separated with no apparent competition interactions as the total biomass production is similar to the isolated plants. However, Qs seems to take advantage of the highly proliferated fungal symbiotic associations that naturally occur in Pp and probably colonizing Qs roots by contact or by altering the community and diversity of organisms in the soil surrounding the roots and facilitating the occurrence of other fungi symbiosis. A clear facilitation interaction of Pp over Qs occurred, emphasised by a 50\% increase in one-side leaf area between mycorrhized and non-mycorrhized Qs plants. Note that this higher leaf area construction ability was independent of the $\mathrm{N}$ content which was similar between infected and non-infected plants. Future work should focus on other leaf nutrients analysis, namely $\mathrm{P}$, which is more closely related with mycorrhizae symbioses. On the other hand, we clearly observed that Pp is highly dependent on such fungi symbiosis, as already observed by other authors [33]. Non-infected Pp showed less than half the leaf $\mathrm{N}$ content with an impact of leaf area and concomitantly growth.

\subsection{Bridging the Conclusions to Practical Field Questions: Study Limitations and Research Needs}

We are aware that transferring the results of pot experiments to natural conditions has obvious limitations and the ability to reproduce the plants' development in their natural environment is challenging (most likely virtually impossible). In this study we had no intentions of mimicking natural conditions but instead chose to create artificial optimum conditions for plants to grow and to investigate the biomass development of Qs and Pp in conspecific (intraspecific) and heterospecific (interspecific) mixtures. We were particularly interested in the investigation of root development in the first months of plant development, as roots are key biomass elements in plant establishment success [34]. We found that the soil exploitation by roots is completely different between the two species.

The mixture of Qs and Pp occurs naturally in mainland Portugal, especially in central-southwest regions with a milder climate, indicating that both species do not segregate. In these regions we observe that cork oaks naturally regenerate under the canopies of stone pine, an event most probably linked with the proximity of seed sources, resulting from a combination of spontaneous colonization of both species over the same environment [9]. It is likely that cork oaks also take advantage of the shading conditions created by pines, which attenuates excessive radiation and heat during summer. At some point in time, pines need to be removed in order to allow the cork oaks to grow, otherwise they remain as saplings for several years, as we observed frequently in moderate to high density stands.

There is also empirical evidence that in some regions of central-southwest Portugal, the rate of cork oak establishment success is higher in areas previously occupied by another land use type other than oaks. We hypothesise a change in soil microbiology that, for some reason, facilitates cork oaks establishment. This study also points to soil mediators. 
As a final remark, we suggest complementarity or even facilitation interactions between plants growing in interspecific mixtures but potential competition when mixed with siblings. We should be able to say that under field condition without limited environmental conditions, the mixture of cork oak with stone pine should be more advantageous than the mixture with individuals of the same species. The fact that Pp tends to mycorrhize intensively and sooner than Qs, leads to the hypothesis that Pp should be able to facilitate the establishment of Qs probably through alterations in soil microorganism habitat or by modifying the chemical properties of the soil, facilitating the other species. On the other hand, the fact that in Portugal we do not have cork oak $\times$ stone pine mixtures in more continental and semi-arid regions, clearly shows that more studies are needed in order to understand the species response under more extreme environments.

\section{Conclusions}

During the seedling stage and under ample water and nutrient conditions, the root growth and morphology of Qs and Pp showed contrasting patterns suggesting complementary soil exploitation interactions in interspecific mixtures and potential competition in intraspecific mixtures. The mixture of Qs with Pp seems to be advantageous in the first stages of plant development as Pp develop abundant mycorrhizae symbiosis formations which elicit mycorrhization of Qs plants coexisting in the same pot. Further studies are needed to complement these results, namely the establishment of field experiments with cork oaks growing under stone pine canopies. Further greenhouse studies should be also carried out combining biotic and abiotic stresses under mixed stands.

Author Contributions: Conceptualization, A.C.C.; Methodology, A.C.C., A.G. and A.N.; Formal Analysis, A.C.C., A.G. and A.N.; Data Curation, A.C.C., A.N., A.G.; Writing-Original Draft Preparation, A.C.C. and A.G.; Writing-Review \& Editing, A.C.C., A.N., A.G. and J.S.P.

Funding: This research was funded by Fundação para Ciência e Tecnologia I.P. (FCT), Portugal, which funded Correia, A. C. postdoc grant number SFRH/BPD/108858/2015 and for funding the research unit CEF (UID/AGR/00239/2013).

Acknowledgments: We would like to thank João Soares and his workers, from Herdade da Abegoaria, who graciously provided the facilities to harvest the seeds for this experimental study. A.C.C. which to thank Enga Conceição Silva for the numerous discussion about mixed stone pine and cork oak forests in Portugal that, in part, were a challenge to conduct this experiment. Also to two anonymous reviewers that provided valuable comments which greatly improved the manuscript.

Conflicts of Interest: The authors declare no conflict of interest.

\section{References}

1. Acacio, V.; Holmgren, M.; Jansen, P.A.; Schrotter, O. Multiple recruitment limitation causes arrested succession in mediterranean cork oak systems. Ecosystems 2007, 10, 1220-1230. [CrossRef]

2. Chaves, M.M.; Pereira, J.S.; Maroco, J.; Rodrigues, M.L.; Ricardo, C.P.P.; Osorio, M.L.; Carvalho, I.; Faria, T.; Pinheiro, C. How plants cope with water stress in the field. Photosynth. Growth Ann. Bot. 2002, 89, 907-916.

3. Brasier, C.M. Phytophthora cinnamomi and oak decline in southern Europe. Environmental constraints including climate change. Ann. Sci. For. 1996, 53, 347-358. [CrossRef]

4. Camilo-Alves, C.; da Clara, M.I.E.; Ribeiro, N. Decline of Mediterranean oak trees and its association with Phytophthora cinnamomi: A review. Eur. J. For. Res. 2013, 132, 411-432. [CrossRef]

5. David, T.S.; Pinto, C.A.; Nadezhdina, N.; Kurz-Besson, C.; Henriques, M.O.; Quilho, T.; Cermak, J.; Chaves, M.M.; Pereira, J.S.; David, J.S. Root functioning, tree water use and hydraulic redistribution in Quercus suber trees: A modeling approach based on root sap flow. For. Ecol. Manag. 2013, 307, 136-146. [CrossRef]

6. Ibanez, B.; Gomez-Aparicio, L.; Avila, J.M.; Perez-Ramos, I.M.; Maranon, T. Effects of Quercus suber Decline on Woody Plant Regeneration: Potential Implications for Successional Dynamics in Mediterranean Forests. Ecosystems 2017, 20, 630-644. [CrossRef] 
7. Mutke, S.; Calama, R.; González-Martinez, S.C.; Gordo, F.J.; Bono, D.; Gil, L. Mediterranean Stone Pine: Botany and Horticulture. In Horticultural Reviews; Janick, J., Ed.; Wiley Online Library: Hoboken, NJ, USA, 2012; Volume 39.

8. Mutke, S.; Gordo, J.; Climent, J.; Gil, L. Shoot growth and phenology modelling of grafted Stone pine (Pinus pinea L.) in Inner Spain. Ann. For. Sci. 2003, 60, 527-537. [CrossRef]

9. Pausas, J.G.; Blade, C.; Valdecantos, A.; Seva, J.P.; Fuentes, D.; Alloza, J.A.; Vilagrosa, A.; Bautista, S.; Cortina, J.; Vallejo, R. Pines and oaks in the restoration of Mediterranean landscapes of Spain: New perspectives for an old practice-A review. Plant Ecol. 2004, 171, 209-220. [CrossRef]

10. Urbieta, I.R.; Garcia, L.V.; Zavala, M.A.; Maranon, T. Mediterranean pine and oak distribution in southern Spain: Is there a mismatch between regeneration and adult distribution? J. Veg. Sci. 2011, 22, 18-31. [CrossRef]

11. Prevosto, B.; Gavinet, J.; Monnier, Y.; Corbani, A.; Fernandez, C. Influence of neighbouring woody treatments on Mediterranean oak development in an experimental plantation: Better form but weaker growth. For. Ecol. Manag. 2016, 362, 89-98. [CrossRef]

12. Prieto, I.; Armas, C.; Pugnaire, F.I. Water release through plant roots: New insights into its consequences at the plant and ecosystem level. New Phytol. 2012, 193, 830-841. [CrossRef] [PubMed]

13. Fruleux, A.; Bonal, D.; Bogeat-Triboulot, M.B. Interactive effects of competition and water availability on above- and below-ground growth and functional traits of European beech at juvenile level. For. Ecol. Manag. 2016, 382, 21-30. [CrossRef]

14. Pretzsch, H.; Bielak, K.; Block, J.; Bruchwald, A.; Dieler, J.; Ehrhart, H.P.; Kohnle, U.; Nagel, J.; Spellmann, H.; Zasada, M.; et al. Productivity of mixed versus pure stands of oak (Quercus petraea (Matt.) Liebl. and Quercus robur L.) and European beech (Fagus sylvatica L.) along an ecological gradient. Eur. J. For. Res. 2013, 132, 263-280. [CrossRef]

15. Jucker, T.; Bouriaud, O.; Avacaritei, D.; Danila, I.; Duduman, G.; Valladares, F.; Coomes, D.A. Competition for light and water play contrasting roles in driving diversity-productivity relationships in Iberian forests. J. Ecol. 2014, 102, 1202-1213. [CrossRef]

16. Beyer, F.; Hertel, D.; Leuschner, C. Fine root morphological and functional traits in Fagus sylvatica and Fraxinus excelsior saplings as dependent on species, root order and competition. Plant Soil 2013, 373, 143-156. [CrossRef]

17. Bolte, A.; Villanueva, I. Interspecific competition impacts on the morphology and distribution of fine roots in European beech (Fagus sylvatica L.) and Norway spruce (Picea abies (L.) Karst.). Eur. J. For. Res. 2006, 125, 15-26. [CrossRef]

18. Buttner, V.; Leuschner, C. Spatial and temporal patterns of fine-root abundance in a mixed oak beech forest. For. Ecol. Manag. 1994, 70, 11-21. [CrossRef]

19. Hendriks, C.M.A.; Bianchi, F. Root density and root biomass in pure and mixed forest stands of Donglas-fir and Beech. Neth. J. Agric. Sci. 1995, 43, 321-331.

20. Kiaer, L.P.; Weisbach, A.N.; Weiner, J. Root and shoot competition: A meta-analysis. J. Ecol. 2013, 101, 1298-1312. [CrossRef]

21. Meinen, C.; Leuschner, C.; Ryan, N.T.; Hertel, D. No evidence of spatial root system segregation and elevated fine root biomass in multi-species temperate broad-leaved forests. Trees-Struct. Funct. 2009, 23, 941-950. [CrossRef]

22. Del Castillo, J.; Comas, C.; Voltas, J.; Ferrio, J.P. Dynamics of competition over water in a mixed oak-pine Mediterranean forest: Spatio-temporal and physiological components. For. Ecol. Manag. 2016, 382, 214-224. [CrossRef]

23. Chen, W.L.; Koide, R.T.; Eissenstat, D.M. Root morphology and mycorrhizal type strongly influence root production in nutrient hot spots of mixed forests. J. Ecol. 2018, 106, 148-156. [CrossRef]

24. Suz, L.M.; Kallow, S.; Reed, K.; Bidartondo, M.I.; Barsoum, N. Pine mycorrhizal communities in pure and mixed pine-oak forests: Abiotic environment trumps neighboring oak host effects. For. Ecol. Manag. 2017, 406, 370-380. [CrossRef]

25. Cubera, E.; Moreno, G.; Solla, A.; Madeira, M. Root system of Quercus suber L. seedlings in response to herbaceous competition and different watering and fertilisation regimes. Agrofor. Syst. 2012, 85, 205-214. [CrossRef] 
26. Caldeira, M.C.; Lecomte, X.; David, T.S.; Pinto, J.G.; Bugalho, M.N.; Werner, C. Synergy of extreme drought and shrub invasion reduce ecosystem functioning and resilience in water-limited climates. Sci. Rep. 2015, 5, 15110. [CrossRef] [PubMed]

27. Kawaletz, H.; Molder, I.; Annighofer, P.; Terwei, A.; Zerbe, S.; Ammer, C. Pot experiments with woody species-A review. Forestry 2014, 87, 482-491. [CrossRef]

28. Faria, T.; Wilkins, D.; Besford, R.T.; Vaz, M.; Pereira, J.S.; Chaves, M.M. Growth at elevated $\mathrm{CO}_{2}$ leads to down-regulation of photosynthesis and altered response to high temperature in Quercus suber L seedlings. J. Exp. Bot. 1996, 47, 1755-1761. [CrossRef]

29. Fernandez, C.; Lelong, B.; Vila, B.; Mevy, J.P.; Robles, C.; Greff, S.; Dupouyet, S.; Bousquet-Melou, A. Potential allelopathic effect of Pinus halepensis in the secondary succession: An experimental approach. Chemoecology 2006, 16, 97-105. [CrossRef]

30. Monnier, Y.; Vila, B.; Montes, N.; Bousquet-Melou, A.; Prevosto, B.; Fernandez, C. Fertilization and allelopathy modify Pinus halepensis saplings crown acclimation to shade. Trees-Struct. Funct. 2011, 25, 497-507. [CrossRef]

31. Xia, Z.C.; Kong, C.H.; Chen, L.C.; Wang, P.; Wang, S.L. A broadleaf species enhances an autotoxic conifers growth through belowground chemical interactions. Ecology 2016, 97, 2283-2292. [CrossRef] [PubMed]

32. Mazzoleni, S.; Bonanomi, G.; Giannino, F.; Rietkerk, M.; Dekker, S.C.; Zucconi, F. Is plant biodiversity driven by decomposition processes? An emerging new theory on plant diversity. Community Ecol. 2007, 8, 103-113. [CrossRef]

33. Rincon, A.; Alvarez, I.F.; Pera, J. Ectomycorrhizal fungi of Pinus pinea L. in northeastern Spain. Mycorrhiza 1999, 8, 271-276. [CrossRef]

34. Pemán, J.; Voltas, J.; Gil-Pelegrin, E. Morphological and functional variability in the root system of Quercus ilex L. subject to confinement: Consequences for afforestation. Ann. For. Sci. 2006, 63, 425-430. [CrossRef]

(C) 2018 by the authors. Licensee MDPI, Basel, Switzerland. This article is an open access article distributed under the terms and conditions of the Creative Commons Attribution (CC BY) license (http:/ / creativecommons.org/licenses/by/4.0/). 